\title{
Regulation of 3-Hydroxy-3-Methylglutaryl-Coenzyme A Reductase Activity in Murine Epidermis

\author{
Modulation of Enzyme Content and Activation State by Barrier Requirements
}

Ehrhardt Proksch, ${ }^{*}$ Peter M. Elias, ${ }^{*}$ and Kenneth R. Feingold”

*Dermatology and ${ }^{\ddagger}$ Medical Services, Veterans Administration Medical Center, and

University of California School of Medicine, San Francisco, California 94121

\begin{abstract}
Epidermal cholesterol biosynthesis is regulated by barrier function. We quantitated the amount and activation state (phosphorylation-dephosphorylation) of the rate-limiting enzyme, 3-hydroxy-3-methylglutaryl coenzyme A (HMG CoA) reductase, in epidermis before and after barrier disruption. In murine epidermis we found high enzyme activity $(\mathbf{1 . 7 5} \pm 0.02$ $\mathrm{nmol} / \mathrm{min}$ per mg protein). After acute barrier disruption, enzyme activity began to increase after $1.5 \mathrm{~h}$, reaching a maximum increase by $2.5 \mathrm{~h}$, and returned to normal by $15 \mathrm{~h}$. Chronic barrier disruption increased total enzyme activity by 83\%. In normal epidermis, measurement of HMG CoA reductase activity in microsomes isolated in NaF- vs. NaCl-containing buffers demonstrated that $46 \pm 2 \%$ of the enzyme was in the active form. After acute or chronic barrier disruption, a marked increase in the percentage of HMG CoA reductase in the active form was observed. Acute disruption increased enzyme activation state as early as $15 \mathrm{~min}$, reaching a maximum after $\mathbf{2 . 5} \mathrm{h}$, with an increase still present at $15 \mathrm{~h}$, indicating that changes in activation state had a close temporal relationship with barrier function. Increases in total HMG CoA reductase activity occurred only after profound barrier disruption, whereas changes in activation state occur with lesser degrees of barrier disruption. Artificial correction of barrier function prevented the increase in total HMG CoA reductase activity", and partially prevented the increase in enzyme activation. These results show that barrier requirements regulate epidermal cholesterol synthesis by modulating both the HMG CoA reductase amount and activation state. (J. Clin. Invest. 1990. 85:874882.) cholesterol - 3-hydroxy-3-methylglutaryl coenzyme A reductase $\bullet$ permeability barrier $\bullet$ transcutaneous water loss
\end{abstract}

\section{Introduction}

The skin is an active site of cholesterol biosynthesis in both rodents (1-3) and primates (4), accounting for up to $30 \%$ of total body sterol synthesis (2). Of this synthetic activity about $70-80 \%$ is localized to the dermis layer in rodents (5), presumably coming from the pilosebaceous epithelium which remains embedded in the dermis during epidermal-dermal separation (5). The remaining $20-30 \%$ of cutaneous synthetic activity

Address reprint requests to Dr. Feingold, Metabolism Section (111F), Veterans Administration Medical Center, 4150 Clement Street, San Francisco, CA 94121.

Received for publication 7 May 1989 and in revised form $6 \mathrm{No}$ vember 1989.

The Journal of Clinical Investigation, Inc.

Volume 85, March 1990, 874-882 derives from the epidermis (5), which, on a weight basis, can be considered among the most active tissue sites of cholesterol synthesis. Within the epidermis, cholesterol synthesis occurs in both the basal (proliferating) and suprabasal (differentiating) cell layers $(5,6)$.

Cutaneous cholesterol synthesis is influenced neither by dietary cholesterol nor by circulating cholesterol levels $(2,7)$. Furthermore, de novo sterol synthesis, both by confluent cultured keratinocytes and by follicular epithelium, is not influenced by exogenous cholesterol, presumably owing to their paucity of low density lipoprotein (LDL) receptors (8-11). Although systemic factors do not appear to influence epidermal sterol synthesis, local perturbation of the cutaneous permeability barrier by organic solvents or detergents markedly stimulates epidermal cholesterol synthesis, which returns to normal in parallel with normalization of barrier function $(12,13)$. Furthermore, essential fatty acid-deficient (EFAD) ${ }^{1}$ mice, who exhibit a dietarily induced perturbation in barrier function, also demonstrate increased epidermal sterol synthesis $(13,14)$.

In both the solvent-induced and EFAD models, the increase in cholesterol synthesis is localized specifically to the epidermis, with no alterations in dermal cholesterol synthesis $(12-14)$. When the defect in barrier function is corrected by application of a water-impermeable membrane, the increase in epidermal cholesterol synthesis is not observed (12-14). In contrast, when a water vapor-permeable membrane is applied, the increase in epidermal cholesterol synthesis is still observed (15). These studies indicate that barrier function regulates epidermal cholesterol synthesis, and further suggests that water flux itself may serve as the signal.

The enzyme, 3-hydroxy-3-methylglutaryl coenzyme A reductase (HMG CoA reductase), catalyses the conversion of HMG CoA to mevalonic acid. In mammalian systems this step is rate-limiting for cholesterol biosynthesis (16). HMG CoA reductase activity is dependent both on the total quantity of enzyme present and on its activation state. It is now well recognized that HMG CoA reductase can be modulated by a covalent, reversible, phosphorylation-dephosphorylation process with the phosphorylated and dephosphorylated forms of the enzyme in an inactive and active state, respectively $(17-20)$. When the tissue is homogenized in the presence of sodium fluoride ( $\mathrm{NaF}$ ), an inhibitor of dephosphorylation, assays of HMG CoA reductase activity are indicative of the actual activity of the enzyme in situ (18). In contrast, when tissues are homogenized in sodium chloride $(\mathrm{NaCl})$, the en-

1. Abbreviations used in this paper: EFAD, essential fatty acid-deficient (model); HMG CoA, 3-hydroxy-3-methylglutaryl coenzyme A (reductase); TEWL, transepidermal water loss. 
zyme is dephosphorylated (activated), and activity then represents an index of the total quantity of enzyme present (18).

Here we determined whether perturbations in barrier function, measured as transepidermal water loss (TEWL), with either topical acetone, sodium dodecyl sulfate (SDS), tape stripping, or an EFAD diet influence the total quantity or activation state of HMG CoA reductase. These studies show that both total enzyme amount and activation state increase in epidermal homogenates after barrier disruption. Moreover, the increase in both enzyme content and activation state parallels the initial perturbation in barrier function, returning to normal as the barrier recovers. Finally, artificial correction of barrier function with a vapor-impermeable membrane blunts the expected increase in both enzyme content and activation state (21).

\section{Methods}

\section{Materials}

Radioisotopes. $\left[{ }^{14} \mathrm{C}\right] \mathrm{HMG} \mathrm{CoA}(54.2 \mathrm{mCi} / \mathrm{mmol}),\left[{ }^{3} \mathrm{H}\right] \mathrm{mevalonic}$ acid $(300 \mathrm{Ci} / \mathrm{mmol}),\left[{ }^{14} \mathrm{C}\right]$ acetate $(57.5 \mu \mathrm{Ci} / \mathrm{mmol})$, and $\left[{ }^{3} \mathrm{H}\right]$ mevalonolactone $(38.8 \mathrm{Ci} / \mathrm{mmol})$ were purchased from New England Nuclear (Boston, MA).

Chemicals and solvents. SDS and anion exchange silica gel (AG 1-X8, formate form, 200-400 mesh) were purchased from Bio-Rad Laboratories (Richmond, CA). EDTA, glucose-6-phosphate, glucose6-phosphate dehydrogenase ( $400 \mathrm{U} / \mathrm{mg}$ protein), NADP, and dithiotreitol (DTT) were purchased from Sigma Chemical Co. (St. Louis, MO). Acetone and petroleum ether were purchased from Fisher Scientific Co. (Fair Lawn, NJ).

Animals. Male hairless mice between 1 and $3 \mathrm{mo}$ of age $(\mathrm{Hr} / \mathrm{Hr})$ were purchased from Jackson Laboratories (Bar Harbor, ME). They were fed standard mouse diet (Simonsen Animal Vendors, Gilroy, $\mathrm{CA}$ ) and water $a d$ lib. Mice were maintained on an EFAD diet (22) for 7-8 wk until TEWL levels were over 100 parts per million (ppm)/0.5 $\mathrm{cm}^{2}$ per $\mathrm{h}$. Control animals also were fed the EFAD diet, supplemented with corn oil ( $~ 50 \%$ linoleic acid) $4 \mathrm{~d}$ before study, ad lib.

\section{Experimental design}

Disruption of the permeability barrier was achieved by unilateral treatment of one flank of each animal with either absolute acetone or $10 \%$ SDS in distilled water as described in previous publications (12, 13,15 ). The contralateral (control) side was treated with $0.9 \%$ sodium chloride. Additionally, the permeability barrier was disrupted by repeated applications of cellophane tape (four to six times). TEWL rates were measured with an electrolytic water analyzer (Meeco Inc., Warrington, PA) as described previously (12-14), and recorded in parts per million $/ 0.5 \mathrm{~cm}^{2}$ per $\mathrm{h}$ ).

To assess directly the effect of occlusion, which instantly lowers TEWL rates to zero, groups of acetone-treated, SDS-treated, or tapestripped animals were covered with a tightly fitted, water-impermeable membrane (one finger of a latex glove) immediately after treatment (12-15), until just before the animals were killed. In other experiments both flanks of the mice were treated with acetone or SDS, with one side covered while the other side was left uncovered by cutting a window through the Latex wrap.

\section{$\left[{ }^{14} \mathrm{C}\right]$ Acetate and $\left[{ }^{3} \mathrm{H}\right]$ Mevalonolactone incorporation into cholesterol}

Five mice were treated with acetone on one flank and with saline on the contralateral flank. After $2.25 \mathrm{~h}$, the mice were killed, the skin was excised, both acetone and saline treated sides were divided into two parts, and then the undersurface was scraped to remove subcutaneous fat. Each skin sample was separately incubated for $2 \mathrm{~h}$ at $37^{\circ} \mathrm{C}$ in a 2-ml solution of $10 \mu \mathrm{M}$ EDTA in Dulbecco's phosphate-buffered saline (Dulbecco's PBS), calcium $\left(\mathrm{Ca}^{2+}\right)$ - and magnesium $\left(\mathrm{Mg}^{2+}\right)$-free $\left(0.16 \mathrm{M} \mathrm{NaCl}, 0.01 \mathrm{M} \mathrm{Na}_{2} \mathrm{HPO}_{4}, 0.03 \mathrm{M} \mathrm{KCl}, 0.01 \mathrm{M} \mathrm{Na}_{2} \mathrm{HPO}_{4}, 0.01\right.$ $\mathrm{KH}_{2} \mathrm{PO}_{4}, \mathrm{pH}$ 7.4) containing $20 \mu \mathrm{Ci}\left[{ }^{14} \mathrm{C}\right]$ acetate and $5 \mu \mathrm{Ci}\left[{ }^{3} \mathrm{H}\right] \mathrm{meva}-$ lonolactone. The reaction was stopped by immersing the skin in an ice-cooled PBS solution. After drying with paper towels the epidermis was scraped off in one sheet and saponified, extracted, and fractionated, and the incorporation into cholesterol was determined as described previously $(2,3)$. Results were expressed as picomoles per hour per milligram of epidermis. To be certain that disruption of the barrier did not effect the entry of labeled acetate and/or mevalonate into the epidermis tissue samples were incubated at $4^{\circ} \mathrm{C}$ and the amount of labeled acetate and mevalonate in the epidermis was determined after homogenization. The quantities of acetate and mevalonate in the epidermis were similar in saline- and acetone-treated epidermis (acetate: saline $1.53 \pm 0.28$ vs. acetone $1.54 \pm 0.09 \mathrm{nmol} \mathrm{NS}$; mevalonate: saline $0.443 \pm 0.094$ vs. acetone $0.385 \pm .022 \mathrm{pmol}$, NS). Thus, disruption of the permeability barrier does not alter the entry of either acetate or mevalonate into the epidermis during organ culture incubation studies.

\section{Tissue preparation for enzyme assay}

The mice were killed by cervical dislocation, and the skin was excised, divided into treated and control sides, and immediately placed epidermal-side downward onto a covered Petri dish containing crushed ice. The undersurface of the skin pieces was scraped with a sharp scalpel blade to remove excess subcutaneous fat. To ensure equivalent sample sizes, the skin was excised around a half dollar coin, corresponding to the treated area, after first stretching the skin pieces on the Petri dish. Epidermis was separated from dermis initially by four different methods: first, by immersion in 10 mM EDTA in Dulbecco's PBS, at $37^{\circ} \mathrm{C}$ for $40 \mathrm{~min}$; secondly, by immersion in $20 \mathrm{mM}$ DTT in $\mathrm{Ca}^{2+}$ $\mathrm{Mg}^{2+}$-free-PBS $\left(4^{\circ} \mathrm{C}\right.$ for $12 \mathrm{~h}$, or $37^{\circ} \mathrm{C}$ for $1 \mathrm{~h}$ ); thirdly by immersion in $0.15 \%$ trypsin in Dulbecco's modified Eagle's medium $\left(4^{\circ} \mathrm{C}\right.$ for $\left.1.5 \mathrm{~h}\right)$; and fourthly by heating to $55^{\circ} \mathrm{C}$ for $30 \mathrm{~s}$ after using a drop of water for good thermal contact. After treatment, the epidermis was peeled off the dermis in one piece by gently scraping with a scalpel blade, dried on paper towels, minced in small pieces $\left(<1 \mathrm{~mm}^{3}\right)$ with scissors, and stored in small plastic tubes overnight at $-70^{\circ} \mathrm{C}$. Since the highest levels of total HMG CoA reductase activity were obtained with EDTA separation (Fig. 1), this technique was employed in most subsequent experiments. However, for measurement of the activation state of HMG CoA reductase, the heat separation method was used.

\section{Microsomal isolation and enzyme assay}

Four volumes of homogenization buffer $(0.3 \mathrm{M}$ sucrose, $10 \mathrm{mM}$ mercaptoethanol, $10 \mathrm{mM}$ EDTA, sodium salt, $\mathrm{pH}$ 7.4) were added to the minced tissue at $4^{\circ} \mathrm{C}$. For measurement of the activation state of the HMG CoA reductase, either $50 \mathrm{mM}$ sodium chloride or $50 \mathrm{mM}$ sodium fluoride was added. Each tissue was subjected to two separate bursts of a tissue homogenizer (Polytron KinemPCU 2, atica GmbH, Lucerne, Switzerland) for $20 \mathrm{~s}$ at $80 \%$ intensity. A 20 -s pause between the bursts was employed to permit cooling of the tissue. Homogenization was continued with a Fisher Sonic Dismembranator (model 300, Artec Systems Corp., Farmingdale, NY) at 35\% intensity, two times for $5 \mathrm{~s}$ with a pause of $20 \mathrm{~s}$. The homogenate was filtered through surgical gauze soaked in the homogenization buffer, and then centrifuged in a microfuge (TM 11, Beckman Instruments, Inc., Fullerton, CA) at 800 $g$ for $15 \mathrm{~min}$. The pellet was washed with 1 vol of homogenization buffer and recentrifuged at $800 \mathrm{~g}$ for $15 \mathrm{~min}$. The pooled supernatants were then centrifuged in the microfuge at $10,000 \mathrm{~g}$ for $15 \mathrm{~min}$. The $10,000-g$ supernatant was then centrifuged at $100,000 \mathrm{~g}$ for $60 \mathrm{~min}$. in an LB-70 M ultracentrifuge using a 50.3 TI-rotor (Beckman Instruments, Inc.). The supernatant was removed and the microsomal pellet was stored overnight at $-70^{\circ} \mathrm{C}$. HMG CoA reductase activity was determined as described previously by this laboratory (23). HMG CoA reductase activity was expressed as nanomoles of mevalonate synthesized per milligram of protein per minute. Protein was determined with a Bio-Rad Laboratories protein assay dye reagent (24). 


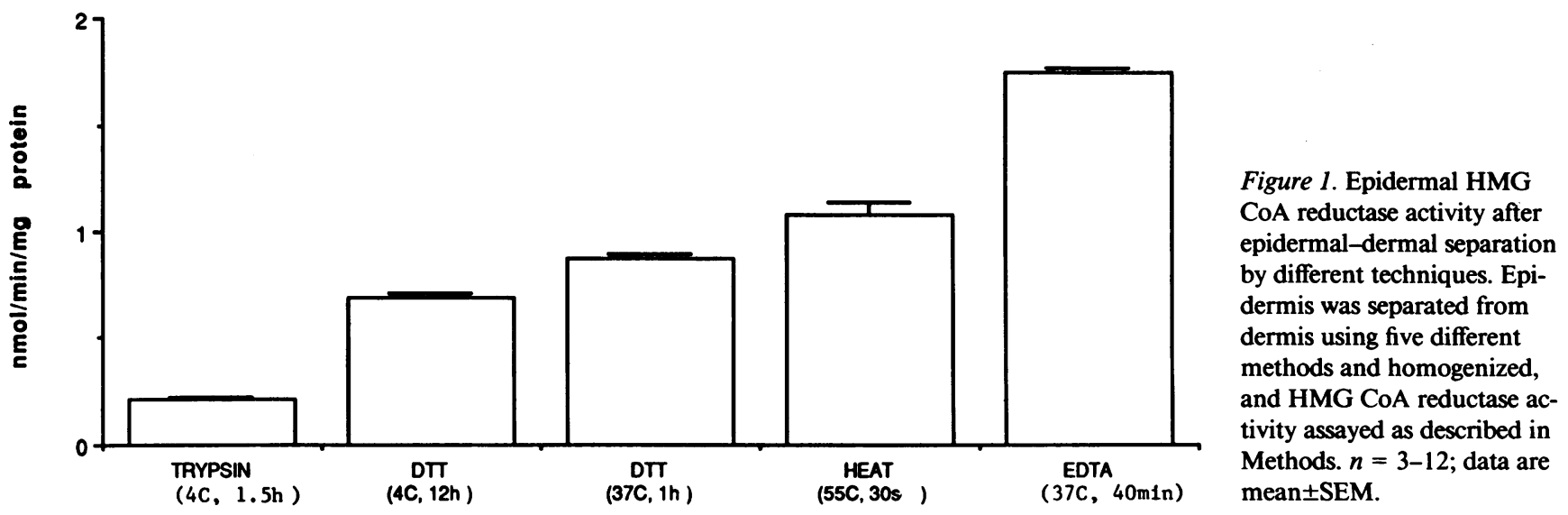

Statistical analysis

Statistical significance was determined using a two-tailed Student's $t$-test. When samples were compared from the same animal, significance was determined using a paired $t$-test.

\section{Results}

$\left[{ }^{14} \mathrm{C}\right]$ Acetate and $\left[{ }^{3} \mathrm{H}\right]$ mevalonolactone incorporation into cholesterol. To determine if the conversion of HMG CoA to mevalonate is the regulatory step in cholesterol biosynthesis in the epidermis, we treated mice with acetone on one side to disturb the barrier (TEWL $930 \pm 40 \mathrm{ppm} / 0.5 \mathrm{~cm}^{2}$ per h). Saline applied to the contralateral side (TEWL 20 \pm 5 ) served as the control. After $2.25 \mathrm{~h}$ skin samples from both sides were incubated for 2 $h$ at $37^{\circ} \mathrm{C}$ in a solution containing $\left[{ }^{14} \mathrm{C}\right]$ acetate and $\left[{ }^{3} \mathrm{H}\right] \mathrm{meva}-$ lonolactone. Whereas acetone treatment resulted in a $68 \%$ increase in $\left[{ }^{14} \mathrm{C}\right]$ acetate incorporation into cholesterol in comparison to the saline-treated side, the incorporation of $\left[{ }^{3} \mathrm{H}\right]-$ mevalonolactone into cholesterol was unchanged (Table I). These results indicate that the stimulation of cholesterol synthesis, induced by perturbations in barrier function, occurs before mevalonate formation, most probably catalyzed by the enzyme HMG CoA reductase.

Assessment of different separatory techniques on total $H M G$ CoA reductase activity. Epidermal HMG CoA reductase activity was compared after separation of the epidermis from the dermis by five different, commonly employed techniques. As can be seen in Fig. 1, enzyme activity was lowest with the

Table I. $\left[{ }^{14} \mathrm{C}\right]$ Acetate and $\left[{ }^{3} \mathrm{H}\right]$ Mevalonolactone Incorporation into Cholesterol after Acetone Treatment

\begin{tabular}{lcc}
\hline & {$\left[{ }^{14} \mathrm{C}\right]$ Acetate } & \multicolumn{2}{c}{$\left[{ }^{3} \mathrm{H}\right]$ Mevalonolactone } \\
\hline \multicolumn{2}{c}{$p$ mol/h per $m g$ epidermis } \\
Acetone $(n=10)$ & $5.55 \pm 0.80$ & $0.00138 \pm 0.00014$ \\
Control $(n=10)$ & $3.31 \pm 0.38$ & $0.00139 \pm 0.00013$ \\
Significance & $P<0.025$ & NS \\
\hline
\end{tabular}

Mice were treated with acetone on one flank and with saline on the contralateral flank. After $2.25 \mathrm{~h}$ the skin of both sides was incubated in a solution containing $\left[{ }^{14} \mathrm{C}\right]$ acetate and $\left[{ }^{3} \mathrm{H}\right]$ mevalonolactone for 2 h at $37^{\circ} \mathrm{C}$. trypsin technique, about three to four times higher with DTT or heat, and highest after separation with EDTA (about eight times higher than with trypsin). Because these results demonstrated that the EDTA method yields optimum enzyme activity, in most subsequent studies we employed the EDTA technique for epidermal-dermal separation.

Effect of acetone or SDS treatment on epidermal HMG $\mathrm{CoA}$ reductase activity. At different periods after acetone, SDS, or saline treatment, the TEWL and the HMG CoA reductase activity were determined on both the acetone- and SDS- vs. saline-treated, contralateral side. Acetone-treatment produced a $>50$-fold increase in TEWL (acetone $=812 \pm 76$ vs. control $=12 \pm 5 \mathrm{ppm} / 0.5 \mathrm{~cm}^{2}$ per h) (Fig. 2, upper panel), which decreased over time such that by seven hours TEWL rates on the acetone-treated side were $135 \pm 62 \mathrm{ppm} / 0.5 \mathrm{~cm}^{2}$ per $\mathrm{h}$. HMG CoA reductase activity was $43 \%$ higher on the acetone side than on the control side $(P<0.01) 2.5 \mathrm{~h}$ after acetone treatment. By $4.5 \mathrm{~h}$ the increase in activity was $34 \%$ over control $(P$ $<0.01$ ), and by $7 \mathrm{~h}$ enzyme activity returned to normal. Likewise, SDS treatment produced a $>50$-fold increase in TEWL with barrier function slowly recovering so that by $15 \mathrm{~h}$ the TEWL was $230 \pm 37 \mathrm{ppm} / 0.5 \mathrm{~cm}^{2}$ per h (Fig. 2, lower panel). HMG CoA reductase activity was slightly increased (8\%) on the SDS side after $1.5 \mathrm{~h}$ (SDS $1.10 \pm 0.05$ vs. saline $1.02 \pm 0.04$, $P<0.01$ ), and was maximally increased $48 \%$ (SDS $1.75 \pm 0.20$ vs. saline $1.18 \pm 0.18, P<0.01$ ) after $2.5 \mathrm{~h}$. However, in contrast to acetone, HMG CoA reductase activity was still increased over controls by $28 \% 7 \mathrm{~h}$ after treatment $(P<0.01)$, only returning to normal by $15 \mathrm{~h}$. These results demonstrate that barrier disruption with either acetone or SDS stimulates HMG CoA reductase activity in the epidermis, and that the return of enzyme activity to normal parallels the recovery of barrier function.

Effect of occlusion on epidermal HMG CoA reductase activity after acetone or SDS treatment. When mice, previously treated with acetone on one side and saline on the other side, were covered with a tightly fitting, water-impermeable latex wrap to artificially restore barrier function, the expected increase in epidermal HMG CoA reductase activity did not occur (Fig. 3). Moreover, in other experiments both flanks were treated with acetone, followed by application of a waterimpermeable wrap to one side, while the other side remained uncovered. HMG CoA reductase activity was $31 \%$ higher on the uncovered than on the covered side $(P<0.01$, data not shown). As in the acetone experiments, after SDS treatment, 

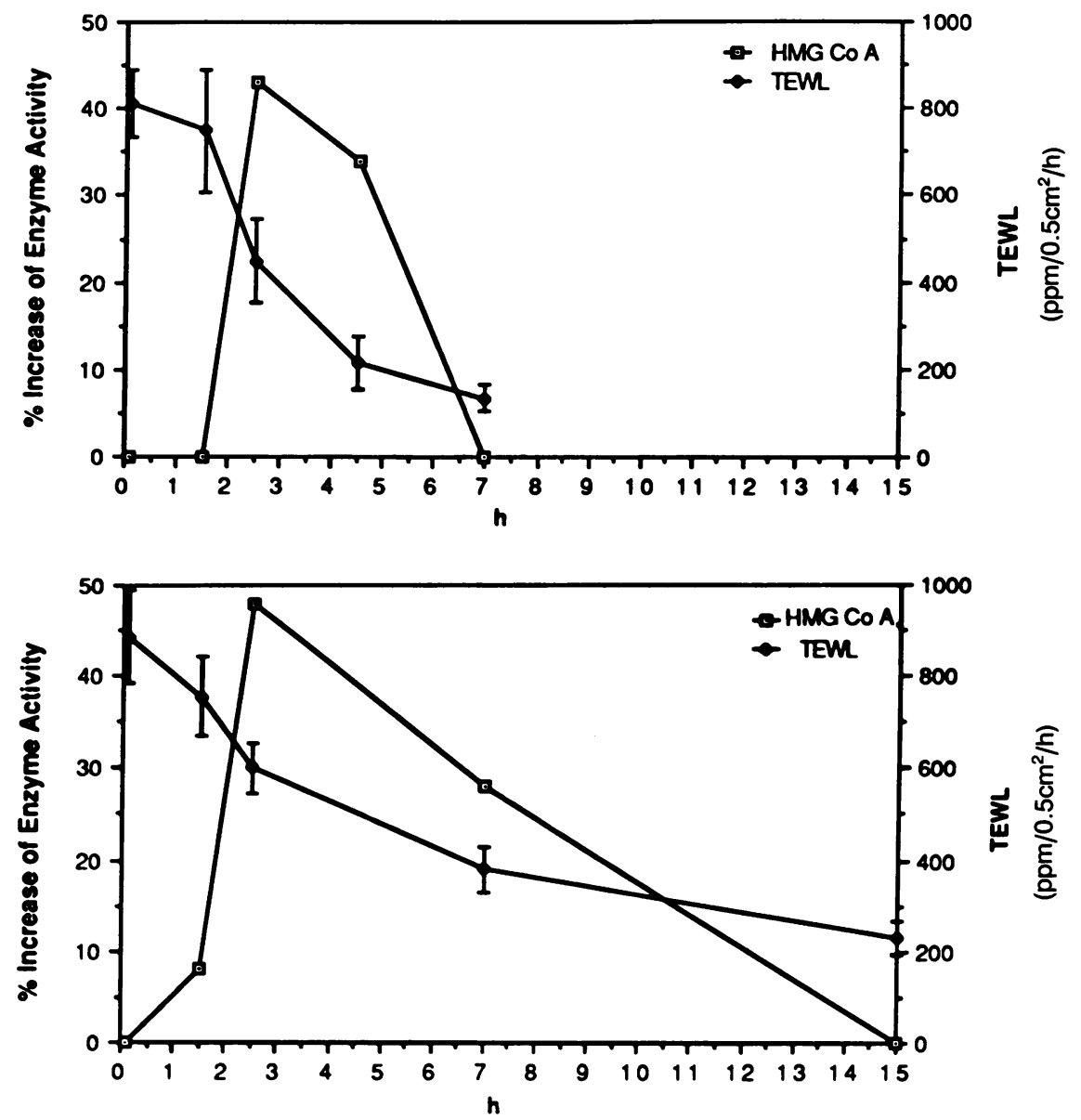

Figure 2. TEWL and HMG CoA reductase activity after barrier disruption with acetone and SDS vs. saline. Mice were treated with acetone (upper panel) or $10 \%$ SDS (lower panel) solution on one flank and with saline on the contralateral flank. At different time points after treatment, TEWL was determined and the skin was excised. Epidermis was separated from dermis by EDTA and HMG CoA reductase activity was determined as described in Methods. Data are mean \pm SEM; error bars that are not seen indicate that the SE fell within the data point $(n=4-11)$.

occlusion prevented the expected increase in epidermal HMG CoA reductase activity (Fig. 3). Likewise, when both flanks were treated with SDS, followed by occlusion of one side while

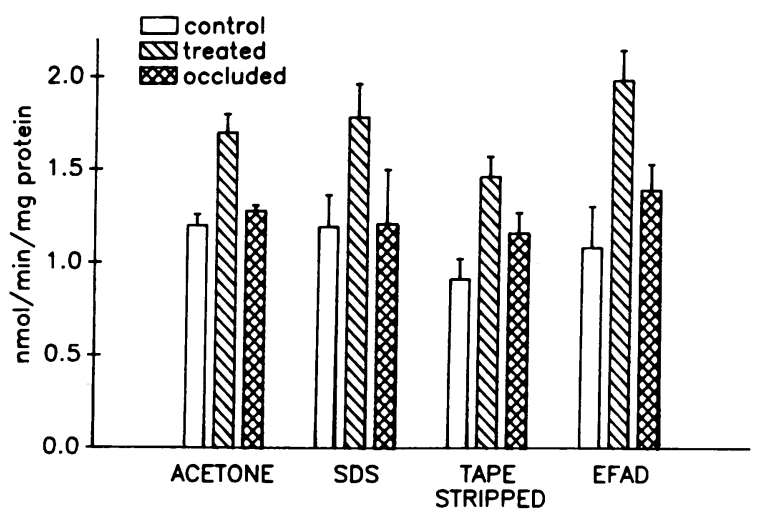

Figure 3. Effect of occlusion on HMG CoA reductase activity. Mice were treated with acetone or SDS (TEWL 800-1,000) and immediately occluded with a tightly fitting latex wrap. Control mice were treated with saline and left exposed to air. After $2.5 \mathrm{~h}$ the skin was excised, epidermis was separated from dermis with EDTA, and HMG CoA total activity was measured as described in Methods. Tape stripped animals were studied $4.5 \mathrm{~h}$ after treatment. EFAD mice were occluded for $3 \mathrm{~d}$. Control mice for the EFAD experiment were refed a linoleic acid containing diet. Data are mean \pm SEM $(n$ $=4-6$ ). the other side remained uncovered, HMG CoA reductase activity was $33 \%$ higher on the uncovered side than on the covered side $(P<0.01$, data not shown). These results demonstrate that occlusion, which artificially restores barrier function, prevents the increase in HMG CoA reductase activity that follows barrier disruption with either acetone or SDS.

Effect of tape-stripping on epidermal HMG CoA reductase activity. As another model of acute barrier disruption we examined the effect of tape stripping on epidermal HMG CoA reductase activity. Tape stripping resulted in a marked disruption in the barrier (TEWL: $1.5 \mathrm{~h} 820 \pm 105 \mathrm{ppm} / 0.5 \mathrm{~cm}^{2}$ per $\mathrm{h}$, 2.5 h $590 \pm 98,4.5$ h $493 \pm 85,6.0$ h $303 \pm 10$ ). In conjunction with this disruption there was a $60 \%$ increase in HMG CoA reductase activity (Fig. 3). Additionally, application of a water-impermeable membrane prevented the increase in HMG CoA reductase activity. These results provide further support for a linkage between barrier function and HMG CoA reductase activity.

Effect of EFAD on HMG COA reductase activity. TEWL and HMG CoA reductase activity were measured in both EFAD and control animals, which had been replenished with linoleic acid for $4 \mathrm{~d}$. In EFAD mice TEWL rates were approximately fourfold higher and the HMG CoA reductase activity was increased $83 \%$ over control animals (Fig. 3). When EFAD mice were occluded with an impermeable wrap on one side for $72 \mathrm{~h}, \mathrm{HMG}$ CoA reductase activity decreased by $34 \%$ in comparison to the nonoccluded EFAD side. The enzyme activity of occluded EFAD-mice was comparable to control animals. 
Occlusion of normal animals for $3 \mathrm{~d}$ produced only a $13 \%$ decrease in HMG CoA reductase activity in comparison to control animals (control animals $1.00 \pm 0.05$, occluded animals $0.88 \pm 0.10 \mathrm{nmol} / \mathrm{min}$ per $\mathrm{mg}$ protein, $n=3, \mathrm{NS}$ ). These results indicate that chronic barrier disruption induced by an EFAD diet also stimulates HMG CoA reductase activity, and that artificial restoration of the barrier decreases the elevated HMG CoA reductase activity in EFAD mice.

Activation state of epidermal HMG COA reductase activity. With either the trypsin, DTT, or EDTA methods for the separation of epidermis from dermis, we did not observe any differences in the activity of HMG CoA reductase in microsomes isolated in a $\mathrm{NaCl}$ vs. $\mathrm{NaF}$ homogenization buffer. This absence of difference between $\mathrm{NaCl}$ and $\mathrm{NaF}$ microsomes may be due to the long in vitro incubation with these solutions required to separate the epidermis from the dermis before the addition of $\mathrm{NaCl}$ or $\mathrm{NaF}$ which may have allowed for alterations in phosphorylation-dephosphorylation state to occur. In contrast, after rapid heat separation (30 s), we observed a ratio of HMG CoA reductase activity in microsomes isolated in $\mathrm{NaF}$ vs. microsomes isolated in $\mathrm{NaCl}$ of $0.46 \pm 0.02$, indicating that $46 \pm 2 \%$ of $\mathrm{HMG}$ CoA reductase is in the active dephosphorylated state. After topical treatment with $0.9 \%$ sodium chloride $(2.5 \mathrm{~h})$, there was no significant difference in the proportion of HMG CoA reductase in the active state in comparison to virgin control epidermis (saline treated [ $n=3$ ] $\mathrm{NaF} / \mathrm{NaCl} 48 \pm 2 \%$ vs. virgin control [ $n=3] 46 \pm 2 \%$ ). We next examined whether isolation of microsomes in $\mathrm{NaCl}$ buffer resulted in a maximal activation (dephosphorylation) of epidermal HMG CoA reductase. After homogenization in $\mathrm{NaCl}$ or $\mathrm{NaF}$ buffer, we incubated epidermal microsomes with liver cytosol which contains phosphatase activity $(23,25)$. This produced a $56 \%$ increase in HMG CoA reductase activity in $\mathrm{NaF}$ microsomes, but no increase in microsomes isolated in $\mathrm{NaCl}$ (Table II). This indicates that during the routine isolation of epidermal microsomes in $\mathrm{NaCl}$ buffer, maximal activation (dephosphorylation) of HMG CoA reductase occurs, an

Table II. Effect of Hepatic Cytosolic Phosphatase on Epidermal HMG CoA Reductase Activity

\begin{tabular}{|c|c|c|}
\hline \multirow[b]{2}{*}{ Incubation mixture } & \multicolumn{2}{|c|}{ HMG CoA reductase activity } \\
\hline & NaF microsomes & $\mathrm{NaCl}$ microsomes \\
\hline & \multicolumn{2}{|c|}{ nmol/min per $\mathrm{mg}$ protein } \\
\hline Buffer alone $(n=3)$ & $0.41 \pm 0.02$ & $0.84 \pm 0.02$ \\
\hline $\begin{array}{l}\text { Buffer + liver cytosol } \\
\quad(n=3)\end{array}$ & $0.70 \pm 0.04$ & $0.87 \pm 0.06$ \\
\hline Significance & $\begin{aligned} & P<0.01 \\
& \quad(\text { two-tailed Student's } \\
&\quad t \text { test })\end{aligned}$ & NS \\
\hline
\end{tabular}

Mouse epidermis was homogenized in a buffer containing either 50 $\mathrm{mM} \mathrm{NaF}$ or $50 \mathrm{mM} \mathrm{NaCl}$ and the microsomes were isolated.

100-200 $\mu \mathrm{g}$ of washed microsomes was then incubated for $30 \mathrm{~min}$ at $37^{\circ} \mathrm{C}$ in $200 \mu$ l of a mixture of $20 \mu \mathrm{M}$ imidazol, $5 \mathrm{mM}$ DTT, $\mathrm{pH} 7.4$, with or without $5.0 \%$ liver cytosol containing phosphatase prepared as described previously (23). After incubation, the microsomes were reisolated by centrifugation and HMG CoA reductase activity was determined as described in Methods. Data are mean \pm SEM. observation similar to that observed by this and other laboratories to occur in liver microsomes $(18,25)$.

Effect of acetone treatment, SDS treatment, and tape stripping on the activation state of HMG CoA reductase. We next measured the ratio of HMG CoA reductase activity in microsomes isolated in $\mathrm{NaF}$ vs. $\mathrm{NaCl}$ homogenization buffer at different time points following acetone treatment. As early as 15 min after acetone treatment (the earliest time point tested), the ratio of $\mathrm{HMG} \mathrm{CoA}$ reductase activity in $\mathrm{NaF}$ vs. $\mathrm{NaCl}$ microsomes was $61 \pm 4 \%$ (an increase of $32 \%$ in comparison to the ratio in untreated epidermis) (Fig. 4, Table III). Further increases in the ratio of $\mathrm{HMG} \mathrm{CoA}$ reductase activity in $\mathrm{NaF}$ - vs. $\mathrm{NaCl}$-isolated microsomes occurred by $45 \mathrm{~min}$ and by $1.5 \mathrm{~h}$, reaching a maximum of $90 \pm 3 \%$ at $2.5 \mathrm{~h}$ ( $96 \%$ increase). Thereafter, the proportion of HMG CoA reductase in the active form began to decrease so that by 4.5 and $7.0 \mathrm{~h}$ it was $70 \%$ and $64 \%$, respectively. The enzyme activation state remained elevated $15 \mathrm{~h}$ posttreatment. These results demonstrate that acetone treatment results in a marked increase in the proportion of enzyme in the active, dephosphorylated state. Moreover, the proportion of enzyme in the active form paralleled the recovery of barrier function. Additionally, it should be noted that using the heat separation method the total activity of HMG CoA reductase increases by $\sim 50 \%$ (Table III), which is similar to the observations noted above using EDTA separation.

The correlation between transepidermal water loss, total microsomal $\mathrm{HMG} \mathrm{CoA}$ reductase activity (isolated in $\mathrm{NaCl}$ ) and the proportion of activated microsomal enzyme $(\mathrm{NaF} /$ $\mathrm{NaCl})$ at $2.5 \mathrm{~h}$ after acetone treatment is shown in Fig. 5. Increases in activation state occurred after moderate barrier disruption (TEWL > 300), and correlated with the degree of barrier disruption $(r=0.96 ; n=8, P<0.01)$. In contrast, changes in total HMG CoA reductase enzyme activity only occurred after more profound changes in barrier function (TEWL > 550). The extent of the increase in total activity also correlated with the degree of barrier disruption $(r=0.95 ; n$ $=8 ; P<0.01)$. These results demonstrate that the activation state of HMG CoA reductase is sensitive to moderate barrier disruption, whereas increases in enzyme amount occur only after more profound changes in barrier function. Both the increase in the percentage of enzyme in the active state and the increase in total enzyme amount correlated directly with the degree of barrier disruption.

At $2.5 \mathrm{~h}$ after treatment with a $10 \%$ SDS solution $\mathrm{HMG}$ $\mathrm{CoA}$ reductase activity in $\mathrm{NaF}$ vs $\mathrm{NaCl}$ microsomes was $93 \pm 6$, which is $102 \%$ higher than on the control side (Fig. 6). In separate experiments we examined the effect of tape stripping on the activation state of $\mathrm{HMG}$ CoA reductase. At $4.5 \mathrm{~h}$ after tape stripping, we observed a $38 \%$ increase in the activation state (activation state: control, $58 \pm 3 \%$; tape-stripped, $80 \pm 2 \% P$ $<0.001 ; n=4$ in each group). These results are similar to those observed after acetone disruption of the permeability barrier, and further demonstrate the relationship of barrier perturbation and increases in activation state of HMG CoA reductase.

Effect of occlusion on the activation state of epidermal $H M G$ CoA reductase. When acetone-treated mice were covered with a tightly fitting, water-impermeable latex wrap to restore barrier function artificially, only a relatively small increase occurred in the proportion of HMG CoA reductase in the active state (Fig. 6). Likewise, when SDS-treated animals were covered similarly, only a relatively small increase in the activation state of HMG CoA reductase occurred in compari- 


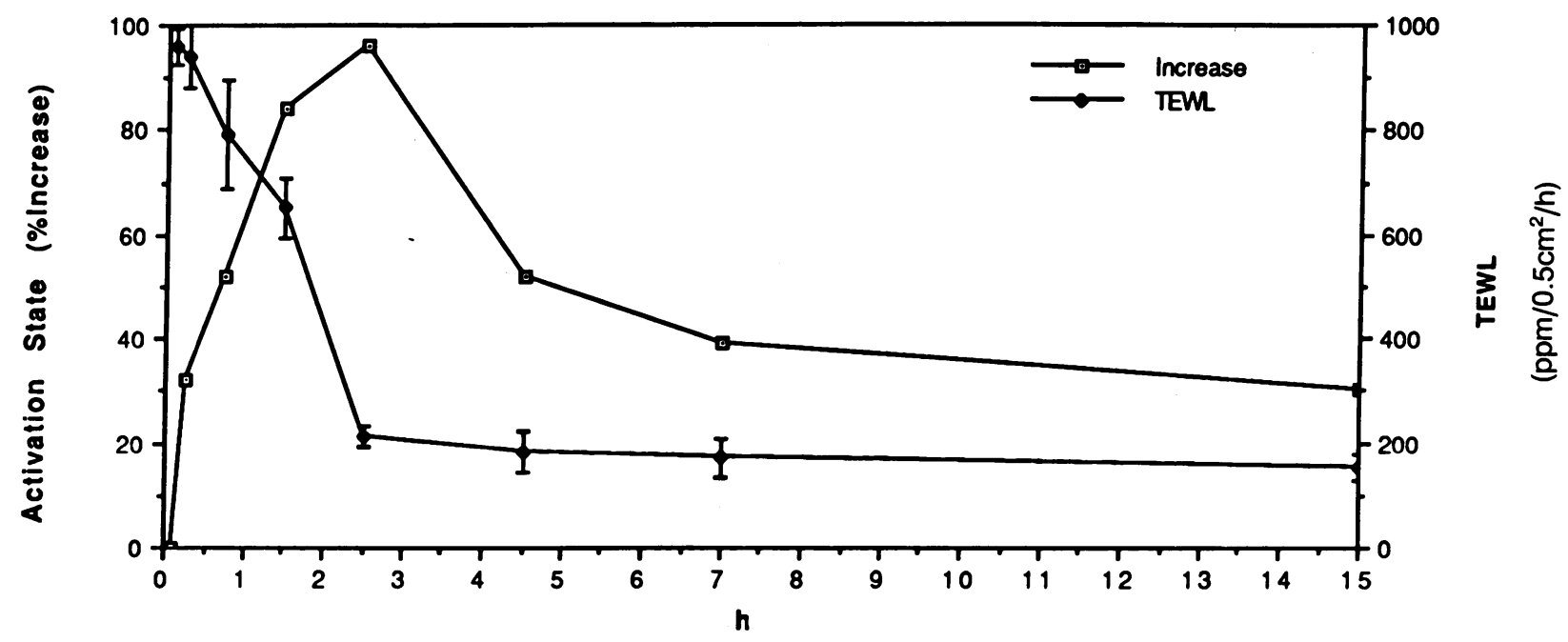

Figure 4. TEWL and activation (dephosphorylation) state of HMG CoA reductase after barrier disruption with acetone vs. control. Mice were treated with acetone on one flank and with saline on the contralateral flank. At different time points after treatment, TEWL was determined and the skin was excised. Epidermis was separated from dermis by heat and one part was homogenized in a NaF and the other part was homogenized in a NaCl-containing buffer. HMG CoA reductase activity was determined as described in Methods. Data are mean \pm SEM. Error bars that are not seen indicate that the SE fell within the data point $(n=3-8)$.

son to controls (Fig. 6). Similarly in tape-stripped animals occlusion also markedly attenuated the increase in activation state (control $58 \pm 3 \%$, tape-stripped $80 \pm 2 \%$, tape-stripped + occlusion $68 \pm 3 \%$ ). These small increases in activation state are comparable in magnitude to those observed in nonoccluded animals after $15 \mathrm{~min}$, presumably because it takes about 10 minutes to place the tightly-fitting Latex wrap. These results demonstrate that occlusion reduces the expected increase in HMG CoA reductase activation state that occurs in mice after either acetone or SDS treatment.

Effect of EFAD on the activation state of $H M G C O A$ reductase. The activation state of HMG CoA reductase also was determined in EFAD vs. control mice. As shown in Fig. 6, a large percentage of HMG CoA reductase was present in the activated form in EFAD mice (115\% increase in comparison to untreated controls). When EFAD mice were covered with a tightly fitting latex wrap for $3 \mathrm{~d}$ while still being maintained on the deficient diet, HMG CoA reductase activation state decreased in comparison to uncovered EFAD mice (covered $78 \pm 4 \%$ vs. uncovered $99 \pm 6 \%$ ), but did not return completely to normal levels (Fig. 6). These results demonstrate, first, that the EFAD state results in activation of HMG CoA reductase and, secondly that artificial restoration of barrier function by occlusion reduces, but does not completely normalize the increase in HMG CoA reductase activation state in EFAD mice.

\section{Discussion}

Although lipids account for a relatively small percentage of total stratum corneum weight, they provide the permeability barrier that is required for terrestrial life $(26,27)$. The ability of the stratum corneum to regulate barrier function can be attributed both to the intercellular location and organization of these lipids into broad, lamellar bilayers $(26,27)$. Whereas most prior studies of the permeability barrier have focused on descriptions of the structure or lipid content of the epidermis, we recently have employed a dynamic approach that exam- ined lipid biosynthesis in response to experimental perturbations of permeability barrier function (12-15). These studies have shown that the epidermis is a highly active site of cholesterol biosynthesis $(5,6)$, and is regulated by perturbation in cutaneous permeability barrier function (12-15). Moreover, the extent of the increase in epidermal cholesterol synthesis correlates directly with the degree of barrier perturbation (12). Finally, artificial restoration of the disturbed barrier with a water-impermeable membrane prevents: $(a)$ the increase in epidermal cholesterol synthesis; $(b)$ lipid reaccumulation; and (c) barrier recovery $(12-15)$.

In the present study we measured the incorporation of both $\left[{ }^{14} \mathrm{C}\right]$ acetate (starting point of cholesterol biosynthesis) and $\left[{ }^{3} \mathrm{H}\right]$ mevalonolactone (post-HMG CoA reductase step) into cholesterol. After acetone disruption of the barrier there was a $67 \%$ increase in $\left[{ }^{14} \mathrm{C}\right]$ acetate but no change in $\left[{ }^{3} \mathrm{H}\right]$ mevalonolactonate incorporation into cholesterol. This demonstrates that the initial increase in cholesterol synthesis induced by barrier disruption occurs before the formation of mevalonate. To determine whether the increase in cholesterol synthesis after barrier disruption is due to an effect on HMG CoA reductase activity, we next measured enzyme activity.

Barrier disruption with either the organic solvent, acetone; the detergent, SDS; or by tape stripping was associated with an increase in the total activity of epidermal HMG CoA reductase activity (with a 1.5-h time delay). Pertinently, the level of increase in total epidermal HMG CoA reductase activity correlated directly with the extent of disturbance in barrier function. Moreover, as barrier function returned towards normal, the levels of total enzyme activity also declined towards normal. After SDS treatment, both barrier recovery and total HMG CoA reductase activity declined more slowly than after acetone treatment (Fig. 2). This difference may be due to the fact that acetone mainly extracts lipids and quickly evaporates from the skin surface, whereas SDS has a more general effect on epidermal proteins, as well as lipids (28). Since the time course of HMG CoA reductase activity after barrier disruption 
Table III. Time Course of Activation (Dephosphorylation) State of HMG CoA Reductase after Acetone Treatment

\begin{tabular}{|c|c|c|c|c|c|}
\hline \multirow[b]{2}{*}{ Time } & \multicolumn{3}{|c|}{ HMG CoA reductase activity } & \multirow{2}{*}{$\begin{array}{l}\text { Portion } \\
\text { of enzyme } \\
\text { in active } \\
\text { state }\end{array}$} & \multirow{2}{*}{$\begin{array}{l}\text { Increase } \\
\text { treated/ } \\
\text { controls }\end{array}$} \\
\hline & TEWL & $\begin{array}{c}\mathrm{NaF} \\
\text { microsomes }\end{array}$ & $\begin{array}{c}\mathrm{NaCl} \\
\text { microsomes }\end{array}$ & & \\
\hline & $\begin{array}{c}p p m / 0.5 \\
c m^{2} \text { per } h\end{array}$ & \multicolumn{2}{|c|}{ nmol/min per $\mathrm{mg}$ protein } & \multicolumn{2}{|c|}{$\%$} \\
\hline $5 \mathrm{~min}$ & & & & & \\
\hline $\begin{array}{l}\quad(n=12) \\
15 \mathrm{~min}\end{array}$ & $960 \pm 35$ & ND & ND & ND & - \\
\hline$(n=3)$ & $940 \pm 60$ & $0.31 \pm 0.02$ & $0.52 \pm 0.02$ & $61 \pm 4^{\ddagger}$ & 32 \\
\hline $45 \mathrm{~min}$ & & & & & \\
\hline $\begin{array}{l}(n=4) \\
1.5 \mathrm{~h}\end{array}$ & $793 \pm 104$ & $0.50 \pm 0.01$ & $0.72 \pm 0.03$ & $70 \pm 2^{\ddagger}$ & 52 \\
\hline $\begin{array}{l}\quad(n=8) \\
2.5 \mathrm{~h}\end{array}$ & $652 \pm 58$ & $0.72 \pm 0.02$ & $0.85 \pm 0.03$ & $85 \pm 3^{\ddagger}$ & 84 \\
\hline $\begin{array}{l}(n=4) \\
4.5 \mathrm{~h}\end{array}$ & $213 \pm 19$ & $0.70 \pm 0.02$ & $0.78 \pm 0.02$ & $90 \pm 3^{\ddagger}$ & 96 \\
\hline $\begin{array}{c}(n=3) \\
7.0 \mathrm{~h}\end{array}$ & $180 \pm 40$ & $0.54 \pm 0.03$ & $0.77 \pm 0.03$ & $70 \pm 3^{\ddagger}$ & 52 \\
\hline$(n=3)$ & $171 \pm 35$ & $0.44 \pm 0.03$ & $0.69 \pm 0.01$ & $64 \pm 3^{\ddagger}$ & 39 \\
\hline $\begin{array}{l}15.0 \mathrm{~h} \\
\quad(n=3)\end{array}$ & $153 \pm 23$ & $0.34 \pm 0.01$ & $0.56 \pm 0.01$ & $60 \pm 1^{\ddagger}$ & 30 \\
\hline
\end{tabular}

Mice were treated with acetone on one flank and with saline on the contralateral flank. At different time points after treatment, TEWL was determined and the skin was excised. Epidermis was separated from dermis by heat, and one part was homogenized in a NaF and the other part was homogenized in a NaCl-containing buffer. HMG CoA reductase activity was determined as described in Methods. * Control data derive from 12 animals with an activation state of $46 \pm 2 \%$.

${ }^{\ddagger}$ Significant difference from controls: $P<0.01$. ND, not determined.

is similar to the kinetics of cholesterol synthesis under similar conditions $(12,13)$, and only $\left[{ }^{14} \mathrm{C}\right]$ acetate but not $\left[{ }^{3} \mathrm{H}\right]$ mevalonolactone incorporation is increased, this strongly suggests that an increase in HMG CoA reductase activity may be the initial step that leads to accelerated cholesterol synthesis and ultimately to restoration of barrier function (15). The link of HMG CoA activity to barrier function is strengthened further by the occlusion experiments: when barrier function is artificially restored by application of a vapor-impermeable wrap, no increase in epidermal HMG CoA reductase activity occurs after either acetone treatment, SDS treatment, or tape stripping.

The essential fatty acid model is more complex than the acetone/SDS models, because epidermal hyperplasia accompanies the barrier abnormality $(14,29)$. We found that the total activity of epidermal HMG CoA reductase is markedly increased in EFAD animals. Hence, the occlusion experiments are particularly pertinent here: artificial restoration of barrier function in EFAD mice with a water-impermeable wrapping led to a significant, but incomplete reduction in epidermal HMG CoA reductase activity, presumably because occlusion only partially reverses the hyperproliferation (Proksch, E., P. M. Elias, and K. R. Feingold, manuscript in preparation). DNA synthesis and cell division requires increases in HMG CoA reductase activity to provide both cholesterol and iso-

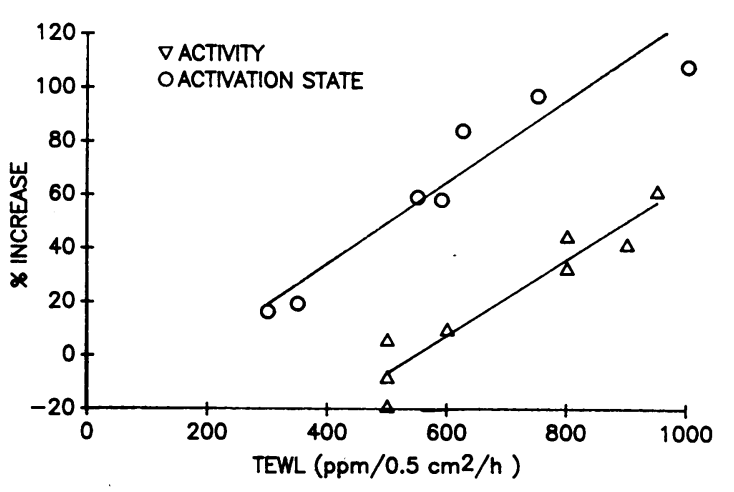

Figure 5. Correlation between TEWL and increases in HMG CoA reductase. Mice were treated with acetone to induce various degrees of barrier disruption as measured by TEWL. After $2.5 \mathrm{~h}$ the skin was excised, the epidermis was separated from dermis by heat treatment, and microsomes were isolated in either $\mathrm{NaCl}$ or $\mathrm{NaF}$ buffer. The activity of $\mathrm{HMG}$ CoA reductase in microsomes isolated in the $\mathrm{NaCl}$ is indicative of the total enzyme content. The ratio of HMG CoA reductase activity in microsomes isolated $\mathrm{NaF}$ vs. $\mathrm{NaCl}$ is indicative of the activation state. The correlation coefficient for total activity $r$ $=0.95 ; n=8 ; P<0.01$, activation state $r=0.96, n=8 ; P<0.01$.

prenoid compounds $(30,31)$. Thus, the results in all four models provide strong evidence that the total activity of HMG CoA reductase is linked to the state of the cutaneous permeability barrier.

HMG CoA reductase activity is modulated by reversible phosphorylation, with the phosphorylated and dephosphorylated forms of the enzyme being inactive and active, respectively (16-20). When tissues are homogenized in the presence of $50 \mathrm{mM}$ sodium fluoride, an inhibitor of dephosphorylation, assays of HMG CoA reductase activity are indicative of the activity of the enzyme present in situ (18). In contrast, when tissues are homogenized in sodium chloride, the enzyme is dephosphorylated (activated), and assays then represent an index of the total quantity of enzyme present in the tissue (18). Under basal conditions $\sim 50 \%$ of epidermal HMG CoA reductase is in the activated form, a finding similar to that in other mammalian tissues, with the exception of liver, where only $15-30 \%$ of the enzyme is activated $(17,18,20,23)$. As observed in liver $(18,25)$, phosphatase treatment of $\mathrm{NaCl}$-isolated microsomes did not result in an increase of HMG CoA reductase activity (Table II), indicating that the isolation of the microsomes in $\mathrm{NaCl}$-containing buffers results in virtually complete activation of the enzyme.

Whereas treatment of mice with acetone produced an increase in total enzyme activity $1.5 \mathrm{~h}$ after treatment, an increase in activation state occurred much sooner: i.e., by $15 \mathrm{~min}$ after barrier perturbation, peaking at $2.5 \mathrm{~h}$ (96\% increase). In conjunction with the $43 \%$ increase in total enzyme amount, this increase in activation state results in an overall 2.8 -fold $(180 \%)$ increase in enzyme activity at $2.5 \mathrm{~h}$. Whereas total HMG CoA reductase activity returned to normal by $7 \mathrm{~h}$, the activation state remained increased even at $15 \mathrm{~h}$ (Note: TEWL rates also are still greater than normal at $15 \mathrm{~h}$ [Fig. 4].) This shows that modulations in HMG CoA reductase activation state are more closely coupled to fluctuations in barrier function than is enzyme amount. Virtually identical results were observed after SDS or tape stripping disruption of the barrier. These results should be compared with studies in liver. Obser- 


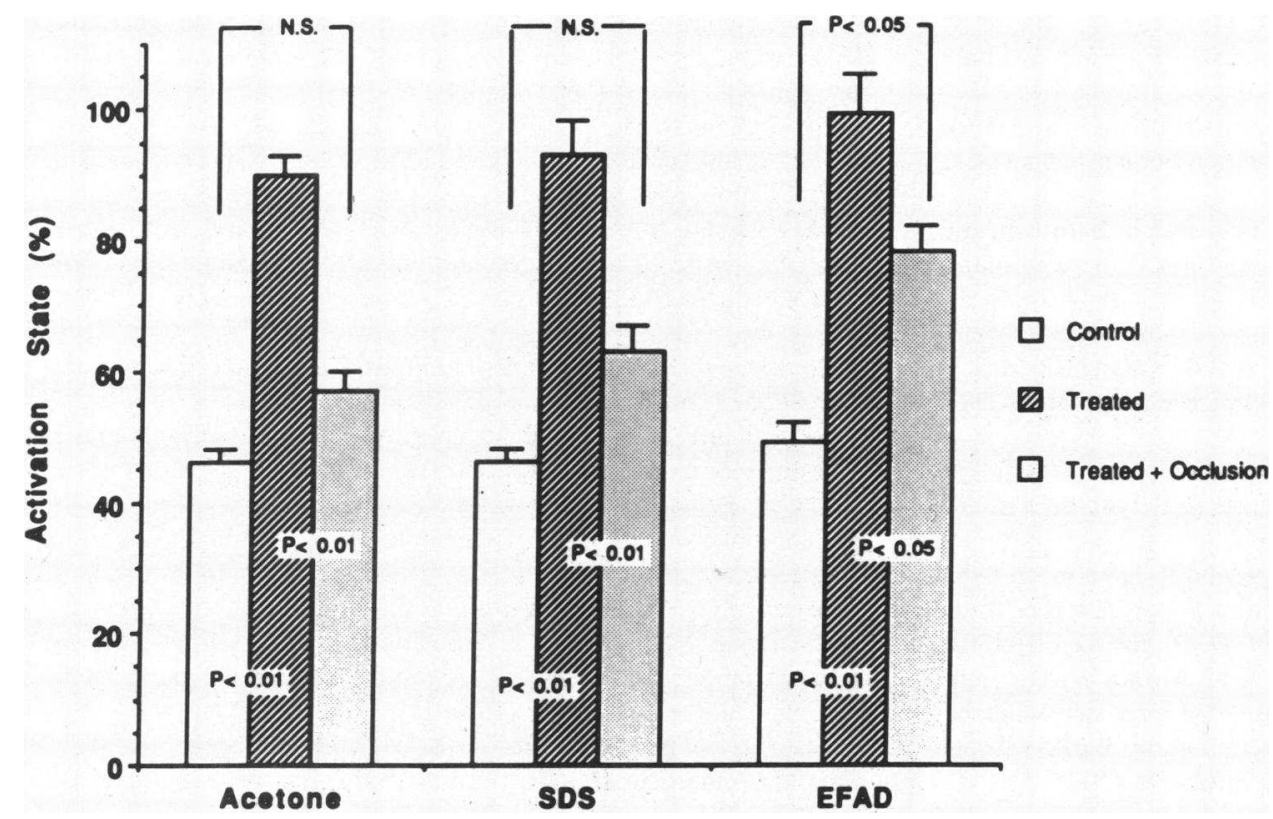

Figure 6. Effect of occlusion on HMG CoA reductase activation (dephosphorylation) state in mouse epidermis. Mice were treated as described under Fig. 3, except that epidermis was separated from dermis by heat treatment. One part of the epidermis was homogenized in $\mathrm{NaF}$ and the other part in $\mathrm{NaCl}$ containing buffers. The HMG CoA reductase was measured as described in Methods $(n=3-5)$. Data are mean \pm SEM. vations in the liver have suggested that the short term $(<1 \mathrm{~h})$ regulation of HMG CoA reductase activity is entirely modulated by changes in activation state with enzyme concentrations becoming a regulatory mechanism only after extended duration of study (32-34). The chronic regulation of hepatic HMG CoA reductase activity is primarily dependent on the quantity of enzyme present $(18,35,36)$, with only modest changes in catalytic efficiency (37). In the epidermis, however, changes in activation state appear to play a more crucial role in regulating HMG CoA reductase activity. Moreover, recent studies have suggested that the dephosphorylated enzyme is degraded more slowly than phosphorylated enzyme, and it is therefore possible that these rapid changes in phosphorylation state could play a role in determining the quantity of enzyme present in the epidermis (38).

With acetone treatment, increases in total HMG CoA reductase activity seems to occur only after profound barrier disruption (TEWL $>550 \mathrm{ppm} / 0.5 \mathrm{~cm}^{2}$ per h), whereas changes in activation state seem to occur in association with lesser degrees of barrier disruption (TEWL $>300 \mathrm{ppm} / 0.5$ $\mathrm{cm}^{2}$ per h) (Fig. 5). Thus, in epidermis regulation of cholesterol biosynthesis after profound barrier disruption occurs via changes both in the amount of enzyme protein and in the activation state, whereas with moderate barrier disruption changes essentially are limited to the activation state alone.

Of particular note is that occlusion prevented the expected increase in HGM CoA reductase activation state after acetone treatment, SDS treatment, and tape stripping. The small increases that were observed could be ascribed to rapid changes in the phosphorylation state that occur during the 10-min period required to place the tightly-fitted latex wrap.

There was a surprising $99 \%$ activation of HMG CoA reductase in EFAD mice, implying that chronic barrier disruption because of linoleic acid deprivation results in complete activation of the enzyme. The $99 \%$ activation state in EFAD mice represents a $115 \%$ increase in comparison to normal mice, which together with an increase in enzyme amount of $83 \%$, equates to an overall, fourfold (293\%) increase in total enzyme activity. Occlusion of EFAD mice only partly decreased enzyme activity, presumably because occlusion does not completely reverse the hyperproliferative state. Enhanced enzyme activity would be required to maintain tissue supplies of cholesterol and isoprenoids required for DNA replication and cell growth $(30,31)$.

In summary, these results demonstrate that the increase in cholesterol synthesis which occurs in the epidermis after barrier disruption can be attributed both to stimulation of HMG CoA reductase content and activity. The specific relationship of this enhanced activity to barrier function is supported further by the blockade of both increased total enzyme activity and enzyme activation following application of an occlusive wrap. These results further suggest that modulations in epidermal HMG CoA activity could directly influence barrier function, a concept supported by recent studies that demonstrate changes in barrier function after topical lovastatin treatment (39).

\section{Acknowledgments}

Bil Chapman capably prepared the manuscript, and Arthur $\mathbf{H}$. Moser and Barbara E. Brown provided invaluable technical assistance.

This work was supported by National Institutes of Health grant AR 19098 and the Medical Research Service, Veterans Administration. Dr. Proksch is a recipient of a grant from the Deutsche Forschungsgemeinschaft, Bonn-Bad Godesberg, Federal Republic of Germany.

\section{References}

1. Turley, S. D., J. M. Andersen, and J. M. Dietschy. 1981. Rates of sterol synthesis and uptake in the major organs of the rat in vivo. $J$. Lipid Res. 22:551-569.

2. Feingold, K. R., M. H. Wiley, G. MacRae, S. R. Lear, A. H. Moser, G. Zsigmond, and M. D. Siperstein. 1983. De novo sterologenesis in the intact rat. Metab. Clin. Exp. 32:75-81.

3. Feingold K. R., G. MacRae, A. H. Moser, J. Wu, and M. D. Siperstein. 1983. Differences in de novo cholesterol synthesis between the intact male and female rat. Endocrinology. 112:96-103. 
4. Feingold, K. R., M. H. Wiley, A. H. Moser, D. T. Lau, S. R. Lear, and M. D. Siperstein. 1982. De novo sterologenesis in intact primates. J. Lab. Clin. Med. 100:405-410.

5. Feingold, K. R., B. E. Brown, S. R. Lear, A. H. Moser, and P. M. Elias. 1983. Localization of de novo sterologenesis in mammalian skin. J. Invest. Dermatol. 81:365-369.

6. Monger, D. J., M. L. Williams, K. R. Feingold, B. E. Brown, and P. M. Elias. 1988. Localization of sites of lipid biosynthesis in mammalian epidermis. J. Lipid Res. 29:603-612.

7. Andersen, J. M., and J. M. Dietschy. 1977. Regulation of sterol synthesis in 15 tissues of the rat. II. Role of rat and human high and low density plasma lipoproteins and of rat chylomicron remnants. J. Biol. Chem. 252:3652-3657.

8. Brannan, P. G., J. L. Goldstein, and M. S. Brown. 1975. 3-Hydroxy-3-methylglutaryl coenzyme A reductase activity in human hair roots. J. Lipid Res. 16:7-11.

9. Ponec, M., L. Havekes, J. Kempenaar, and B. J. Vermeer. 1983. Cultured human skin fibroblasts and keratinocytes: differences in the regulation of cholesterol synthesis. J. Invest. Dermatol. 81:125-130.

10. Williams, M. L., S. L. Rutherford, A-M. Mommaas-Kienhuis, S. Grayson, B. J. Vermeer, and P. M. Elias. 1987. Free sterol metabolism and LDL-receptor expression as differentiation markers in cultured human keratinocytes. J. Cell Physiol. 132:428-440.

11. Mommaas-Kienhuis, A-M., S. Grayson, M. C. Wijsman, B. J. Vermeer, and P. M. Elias. 1987. LDL receptor expression of keratinocytes in normal and psoriatic epidermis. J. Invest. Dermatol. 89:513517.

12. Menon, G. K., K. R. Feingold, A. H. Moser, B. E. Brown, and P. M. Elias. 1985. De novo sterologenesis in the skin. II. Regulation by cutaneous barrier requirements. J. Lipid Res. 26:418-427.

13. Grubauer, G., K. R. Feingold, and P. M. Elias. 1987. The relationship of epidermal lipogenesis to cutaneous barrier function. $J$. Lipid Res. 28:746-752.

14. Feingold, K. R., B. E. Brown, S. R. Lear, A. H. Moser, and P. M. Elias. 1986. The effect of essential fatty acid deficiency on cutaneous sterol synthesis. J. Invest. Dermatol. 87:588-591.

15. Grubauer, G., P. M. Elias, and K. R. Feingold. 1989. Transepidermal water loss: the signal for recovery of barrier structure and function. J. Lipid Res. 30:323-334.

16. Rodwell, V. W., J. L. Nordstrom, and J. H. Mitschelen. 1976. Regulation of HMG-CoA reductase. Adv. Lipid Res. 14:1-74.

17. Gibson, D. M., and T. S. Ingelbriben. 1978. Reversible modulation of liver hydroxymethylglutaryl CoA reductase. Life Sci. 23:26492664.

18. Brown, M. S., J. L. Goldstein, and J. M. Dietschy. 1979. Active and inactive forms of 3-hydroxy-3-methylglutaryl coenzyme A reductase in the liver of the rat: comparison with the rate of cholesterol synthesis in different physiological states. J. Biol. Chem. 254:51445149.

19. Beg, Z. H., J. A. Shonik, and H. B. Brewer, Jr. 1978. HMG CoA reductase: regulation of enzymatic activity by phosphorylation and dephosphorylation. Proc. Natl. Acad. Sci. USA. 75:3678-3682.

20. Kenelly, P. J., and V. W. Rodwell. 1985. Regulation of 3-hydroxy-3-methyl-glutaryl coenzyme A reductase by reversible phosphorylation. J. Lipid Res. 26:903-914.

21. Proksch, E., P. M. Elias, and K. R. Feingold. 1989. Quantitation, localization, and modulation of epidermal HMG CoA reductase activity. Clin. Res. 37:620a. (Abstr.)

22. Williams, M. A., K. T. Tamai, S. Hincenbergs, and D. J. McIntosh. 1972. Hydrogenated coconut oil and tissue fatty acids in EPA-depleted and EFA-supplemented rats. J. Nutr. 102:847-856.
23. Feingold, K. R., M. H. Wiley, A. H. Moser, S. R. Lear, and M. D. Siperstein. 1983. Activation of HMG-CoA reductase by microsomal phosphatase. J. Lipid Res. 24:290-296.

24. Gotham, S. M., P. J. Frye, and W. K. Paterson. 1988. Measurement of soluble proteins using a modified Bradford assay. Anal. Biochem. 173:353-358.

25. Feingold, K. R., M. H. Wiley, A. H. Moser, and M. D. Siperstein. 1983. Altered activation state of hydroxymethylglutaryl-coenzyme A reductase in liver tumors. Arch. Biochem. Biophys. 226:231241.

26. Elias, P. M. 1983. Epidermal lipids, barrier function, and desquamation. J. Invest. Dermatol. 80:44-49.

27. Williams, M. L., and P. M. Elias. 1987. The extracellular matrix of stratum corneum: role of lipids in normal and pathological function. CRC Crit. Rev. Ther. Drug Carrier Syst. 3:95-122.

28. Imokawa, G., and Y. Mishima. 1979. Cumulative effect of surfactants on cutaneous horney layers: adsorption onto human keratin layers in vivo. Contact Dermatitis. 5:357-366.

29. Lowe, N. J., and R. B. Stoughton. 1977. Essential fatty acid deficient hairless mouse: a model of chronic epidermal hyperproliferation. Br. J. Dermatol. 96:155-162.

30. Siperstein, M. D. 1984. Role of cholesterologenesis and isoprenoid synthesis in DNA replication and cell growth. J. Lipid Res. 25:1462-1267.

31. Siperstein, M. D., H. DoVale, and J. R. Silber. 1987. Relationship of cholesterol to DNA synthesis in normal and cancerous cells. In Drugs Affecting Lipid Metabolism. R. Paoletti, et al., editors. Springer-Verlag, Berlin. 1-8.

32. Arebalo, R. E., Jr., E. Hargrave, and T. J. Scallen. 1981. The in vivo regulation of rat liver 3-hydroxy-3-methylglutaryl coenzyme A reductase: enzyme phosphorylation as an early regulatory response after intragastric administration of mevalonolactone. Proc. Natl. Acad. Sci. USA. 77:6249-6433.

33. Erickson, S. K., M. A. Shrewsbury, R. G. Gould, and A. D. Cooper. 1980. Studies of the mechanisms of the rapid modulation of 3-hydroxy-3-methylglutaryl coenzyme A reductase in intact liver by mevalonolactone and 25-hydroxy-cholesterol. Biochim. Biophys. Acta. 620:70-79.

34. Arebalo, R. E., J. E. Hargrave, and T. J. Scallen. 1981. The in vivo regulation of rat liver 3-hydroxy-3-methylglutaryl coenzyme A reductase: phosphorylation of the enzyme as an early regulatory response following cholesterol feeding. J. Biol. Chem. 256:571-574.

35. Edwards, P. A., D. Lemongello, J. Kane, I. Schecter, and A. M. Fogelman. 1980. Properties of purified rat hepatic 3-hydroxy-3-methylglutaryl coenzyme A reductase and the regulation of enzyme activity. J. Biol. Chem. 255:3715-3725.

36. Kleinsek, D. A., A. M. Jabalquinto, and J. W. Porter. 1980. In vivo and in vitro mechanisms regulating rat liver $\beta$-hydroxy- $\beta$-methylglutaryl coenzyme A reductase activity. J. Biol. Chem. 255:39183923.

37. Hardgrave, J. E., R. A. Heller, M. G. Herrera, and T. J. Scallen. 1979. Immunotitration of 3-hydroxy-3-methylglutaryl-coenzyme A reductase in various physiological states. Proc. Natl. Acad. Sci. USA. 76:3834-3838.

38. Parker, R. A., S. J. Miller, and D. M. Gibson. 1989. Phosphorylation of native 97-KDa 3-hydroxy-3-methylglutaryl coenzyme A reductase from rat liver. J. Biol. Chem. 264:4877-4887.

39. Man, M.-Q., K. R. Feingold, B. E. Brown, G. K. Menon, S. K. Pillai, and P. M. Elias. 1989. Lovastatin perturbation of epidermal barrier function: Functional, morphological, and biochemical characteristics. Clin. Res. 37:529a. (Abstr.) 